\title{
La cátedra de filosofía en los planes ilustrados del Virreinato de la Nueva Granada
}

Diana Soto Arango

En este artículo nos proponemos reseñar los nuevos estudios y en concreto los planes para la cátedra de filosofía, que se proyectaron en la ciudad de Santa Fe y Quito desde mediados del Siglo XVIII. Estas reformas tenían como fundamento la corriente ilustrada que impulsaba una nueva filosofía: "la útil", que llevaba implícita la enseñanza de la filosofía natural newtoniana.

En el campo educativo, los ilustrados trataron de impulsar sendas reformas en la enseñanza universitaria y en la organización y funcionamiento de los colegios mayores. Entre los hechos principales que influyeron en el planteamiento de las anteriores reformas, pueden destacarse, entre otros, la expulsión de los jesuitas y el deplorable estado académico organizativo en el que se encontraban las universidades españolas y coloniales.

En el virreinato de la Nueva Granada se crearon por la época colonial en las capitales de Audiencia, como eran Santa Fe, Quito, Panamá y Caracas, nueve universidades y/o colegios mayores. En estas ciudades la vida cultural y académica tuvo un mayor movimiento desde los inicios de la filosofía ilustrada. La intelectualidad criolla entró a manejar otros conceptos, y por tanto, se dio un viraje en los planteamientos educativos, sociales, económicos y políticos del virreinato. Sin embargo, debe señalarse que en la capital del virreinato, la ciudad de Santa Fe, fue donde se organizaron las mayores polémicas académico-políticas.

En el virreinato de la Nueva Granada, sin lugar a dudas, el plan de estudios más importante que se presentó fue el del fiscal Francisco Moreno y Escandón, quizá por ser el primero y por la filosofía y método planteados, que abrieron la brecha hacia las nuevas ideas de la ilustración en el corto período de aplicación que tuvo el plan. En la misma línea del planteamiento ilustrado de Moreno, y con las características de crear universidad pública, se encuentra el plan de estudios del arzobispo -virrey Caballero y Góngora, presentado en 1787, para los colegios mayores de la ciudad de Santa Fe. Sin embargo, este plan sólo fue una propuesta que se quedó en el papeleo de la máquina burocrática gubernamental.

Otro plan de pensamiento ilustrado, pero más avanzado en los pensamientos radicales contra el escolasticismo se encuentra en los estudios y método que presentó don Eloy Valenzuela, para el colegio Pinillos de Mompós, en 1804.

En la universidad de Caracas se presentó una reforma de estudios, con pensamiento ilustrado impuesta por Real Cédula el 5 de septiembre de 1786. Sin embargo este plan no se llevó a la práctica: dos años más tarde otra Real Orden lo dejó sin efecto.

En la universidad de Santo Tomás de Quito, el obispo José Pérez Calama elaboró un plan de estudios en 1791. Este plan conservó el método escolástico, pero a su vez, también planteó el pensamiento moderado de Melchor Cano y señaló la necesidad de pensar la literatura ilustrada y "útil". Este plan no llegó a aprobarse en el Real Consejo de Indias, y por lo mismo no se aplicó.

\footnotetext{
"Docente e investigadora de la Universidad Pedagógica Nacional de Colombia. Coordina el proyecto UPNCOLCIENCIAS "Los estudios superiores en el virreinato de la Nueva Granada". 
Sin embargo, a través de la cátedra de filosofía en la universidad pública quiteña, se enseñó la Anatomía (1797) y posteriormente se crea la cátedra de Botánica (1813). El colegio de San Femando regentado por los dominicos en Quito, en 1802, después de una visita se encontró que la "enseñanza era rutinaria". Por lo anterior el presidente de la Audiencia mandó reformar los estudios de este colegio. El nuevo plan para la cátedra de filosofía lo presentó el doctor Luis Quijano y Carvajal en 1803. En este mismo año se ordenó la aplicación del nuevo plan que señalaba la enseñanza de la filosofía moderna.

Aunque la universidad de San Nicolás de Bari, en Santa Fe, no educó a seglares no puede dejar de mencionarse en este trabajo porque el plan ilustrado del padre general de los agustinos, Francisco Javier Vásquez, en su momento tuvo resonancia cultural, en la capital, por la enseñanza que se impartió sobre las teorías de Newton y Copérnico. En la ciudad de Quito la universidad de San Fulgencio, también regentada por los agustinianos, aplicó mediante decretos el citado plan ilustrado del padre Vásquez.

En este estudio el análisis se centrará en la cátedra de filosofía que proponían estos planes ilustrados, la cual produjo en su época las mayores discusiones por ser en esa enseñanza en donde se centraban el método y la filosofía escolástica.

Debemos señalar que estos planes no se presentaban aislados del movimiento cultural y político que se movía, con mayor fuerza, fuera de los claustros universitarios. Los debates y polémicas universitarias y culturales en la sociedad se pusieron a la orden del día abogando por una "filosofía útil" y una "ciencia patriótica". La gran repercusión de esta filosofía ilustrada se dio en el plano político, quedándose el educativo y económico relegado a una pequeña élite de intelectuales criollos.

\section{La filosofía "útil ", fundamento de la nueva cátedra de filosofía.}

La introducción y defensa de un nuevo sistema filosófico pueden considerarse como los máximos aportes de los planes ilustrados porque, por primera vez, institucionalmente se expone en el nuevo mundo una filosofía que se contrapone al método y filosofía escolásticos, concepción del mundo tradicionalmente imperante.

Estos nuevos planteamientos filosóficos que se cristalizaron en planes educativos, en su mayoría no se aplicaron. Los autores de las nuevas propuestas académicas recibieron diferentes tipos de influencia. Algunos como Mutis, Caballero y Góngora, Pérez Calama, españoles de la metrópoli, se educaron directamente en España. Estos ilustrados, por lo tanto, se convirtieron el las colonias en agentes de difusión científica, señalando nuevos rumbos a la cultura, la educación y la economía en el virreinato.

Por otra parte, criollos como Moreno y Escandón, Valenzuela, Espejo, Luis Quijano y Carvajal, recibieron influencia externa a través de libros, profesores jesuitas, misiones científicas y directamente de los agentes difusores metropolitanos de la nueva filosofía ilustrada $^{359}$. En efecto, se ha llegado a plantear que "Mutis contribuyó como nadie en su

\footnotetext{
${ }^{359}$ En la universidad Javeriana, de Santa Fe de Bogotá, donde se educó el fiscal Moreno y Escandón, desde 1757, el profesor de filosofía, explica a Newton y Copérnico. En el caso de Quito, la universidad Gregoriana contó con un equipo de docentes que enseñaba la filosofía ilustrada y hacia 1761 se defendía públicamente el sistema copernicano. Véase en PACHECO, Juan Manuel.: Ciencia, filosofía y educación en Colombia. Bogotá, ECOE, 1984, pp. 10-11. PALADINES ESCUDERO, Carlos.: "Estudio Introductorio", en Pensamiento ilustrado ecuatoriano. Quito, Banco Central del Ecuador, 1981, pp.32-39. SALDAÑA, Juan José.: "Nacionalismo y ciencia llustrada en América", en Ciencia, Técnica y Estado en la España Ilustrada. Zaragoza, Ministerio de Educación y Ciencia, 1988, pp. 115-129. "La curiosidad científica en Europa, Digitalizado por RED ACADEMICA
} 
interacción de medio siglo con las élites criollas, a aclimatar una cultura científica moderna"360

Estos planes señalan un nuevo concepto de la enseñanza de la filosofía. Se deja atrás la escolástica y se propone una filosofía "útil", que tiene como base la filosofía ligada al conocimiento de las ciencias naturales y de la física experimental.

Este nuevo concepto que trabaja la filosofía no trata de elucubrar cómo es o debe ser la naturaleza según la ortodoxia sino, por el contrario, parte del conocimiento real de la naturaleza a través de las ciencias naturales, utilizando "los principios de la física demostrados por las matemáticas" para elaborar dicha filosofía natural.

Para esa época, en España, un grupo de filósofos y escritores, todos ellos pertenecientes al movimiento ilustrado, creaban gabinetes de historia natural y reunían libros científicos para llevar a cabo experimentos y observaciones; cambiaban el lujo vio superfluo, por instrumentos y máquinas muy costosas a fin de experimentar.

En efecto, en el virreinato de la Nueva Granada, los nuevos planes ilustrados y en concreto la cátedra de filosofía produjeron fuertes discusiones. Se debe tener en cuenta que esta situación se debía a que los enemigos de cualquier innovación y del progreso seguían siendo muy fuertes y contaban con poderosas armas para combatir cualquier desviación, por pequeña que fuera, del dogma y la tradición escolástica. Además, la filosofía era un estudio muy importante en la formación académica porque se le consideraba como "la escala por donde se ascendía a las demás ciencias".

La cátedra de filosofía se encontraba en la Facultad "menor" de Artes y Filosofía. Estos estudios se consideraban la base para poder continuar en una de las carreras de las otras facultades "mayores", que generalmente eran: Teología, Jurisprudencia y Medicina.

Criollos ilustrados, como Francisco Moreno y Escandón y Eloy Valenzuela, se encuentran ante ese avance científico y cambio de mentalidad y se enfrentan a una dura reacción tradicionalista y clerical que quería seguir monopolizando la interpretación científica y filosófica en aras de la aplicación ortodoxa del dogma y la pureza de la fe. Estos criollos asimilaban las ideas ilustradas de una manera particular, teniendo en cuenta las circunstancias sociales y culturales diferentes a las de la España peninsular y en general de Europa ${ }^{361}$. Se señala en los planes de estos criollos ilustrados el estudio del medio

contribuyó a formar vanas academias para reunir y recopilar información de viajeros a fin de estimular el interés por las ciencias naturales". Uno de los primeros visitantes a las colonias españolas bajo el régimen de los Borbones fue Amedie de Frezier, en el virreinato de Perú, 1712-1714. En 1735, bajo los auspicios de la Academia Francesa de las Ciencias y de la Corona española, salió la expedición Geodésica, encabezada por Charles de la Condamine que incluía a científicos como Pedro Bouguer, Luis Godín, Seniergues, Jussieu y a los españoles Antonio Ulloa y Jorge Juan. A fines del siglo XVIII vino también Humbolt a América. Véase en ASTUTO, Philip Louis.: "La llustración en Quito y en Nueva Granada", en Eugenio Espejo (1747-1 795) reformador ecuatoriano de la ilustración. México, Fondo de Cultura Económica, 1969, pp.47- ${ }^{5}$. PUIG - SAMPER, Miguel Angel.: "La ciencia metropolitana y la conciencia nacional en las colonias", en Ciencia, Técnica y Estado en la España Ilustrada, Zaragoza, Ministerio de Educación y Ciencia, 1988, pp. 234-237.

${ }^{360}$ ARBOLEDA, Luis Carlos.: Newton en la Nueva Granada. Elementos inéditos sobre los orígenes de la cultura científica. Cali, Universidad del Valle, julio, 1990, p. 8.

${ }^{361}$ ARBOLEDA, Luis Carlos.: "Acerca del problema de la difusión científica en la periferia: El caso de la física newtoniana en la Nueva Granada" en Revista Latinoamericana de Historia de las Ciencias y la Tecnología. México, Vol. 4, No. 1, enero - abril de 1987, p.8. 
circundante, de ahí la necesidad, según ellos, de estudiar la botánica, la zoología, la química y la mineralogía.

Un ejemplo lo tenemos en el plan de estudios que propone el fiscal Francisco Moreno y Escandón, cuando señala que se debe "purgar la lógica y la metafísica de cuestiones inútiles y reflejas sustituyéndolas por sólidos conocimientos de la naturaleza apoyados en las observaciones y experiencias" ${ }^{362}$.

Por su parte, Eloy Valenzuela ${ }^{363}$ formula una dura crítica a la filosofía que se venía desarrollando en los estudios del virreinato, porque esta filosofía escolástica peripatética, según él, había engendrado en los jóvenes el hastío, desprecio y aún el aborrecimiento de los libros ${ }^{364}$. Si bien es cierto que el plan de estudios de Valenzuela no se aplicó, sin embargo representa un esfuerzo de este criollo por impulsar el pensamiento ilustrado en otro campo diferente de la Expedición Botánica.

El padre Francisco Javier Vásquez ${ }^{365}$ igualmente, en su plan de estudios que se aplica en la Universidad de San Nicolás de Barí en Santa Fe, señala que debe abandonarse el método peripatético-tomista y, por el contrario, recomienda aceptar las corrientes de la filosofía nueva"por ser más útil y provechosa para emprender las demás ciencias y hallar la verdad" ${ }^{366}$.

362 "Método provisional e interino de los estudios que han de observar los colegios de Santa Fe, por ahora y hasta tanto que se erige universidad pública, o su Majestad dispone otra cosa, propuesto por el fiscal Francisco Moreno y Escandón". Santa Fe, 12 septiembre 1774. Archivo Jardín Botánico (A.J.B.) Sección Mutis Legajo 25 folio 3 (numeración nuestra, en adelante "plan de estudios del fiscal Moreno de 1774 "). Este documento se encuentra publicado por HERNANDEZ DE ALBA, G.: Documentos para la historia de la educación en Colombia. 1767 - 1776. Bogotá. Editorial Kelly, tomo IV., 1980, pp. 195 a 227. cita pp. 199-200 y en Boletín de Historia y Antigüedades. Nos. 2,3, 1936. pp. 644-672.

363 Eloy Valenzuela (1756-1834), natural de Girón, murió asesinado en Bucaramanga el 31 de octubre de 1834. Estudió en el Colegio del Rosario, "Cánones de Teología", reemplazó a Mutis en la cátedra de matemáticas. Enseñó la cátedra de filosofía según el nuevo plan de estudios del fiscal Moreno y Escandón, en octubre de 1777. Trabajó como secretario del virrey-arzobispo Caballero y Góngora. Se le llegó a considerar como el segundo en la Expedición Botánica". Elaboró un trabajo sobre la flora de la parroquia de Bucaramanga y fue autor del Plan de estudios y método para el colegio Pinillos de Mompós, que presentó en 1804. En cuanto a sus ideas políticas iniciales se dice que no fue patriota decidido, pero terminó siendo"gran amigo de Bolívar". Véase en BOHORQUEZ CASALLAS, L. La evolución educativa en Colombia. Bogotá, Publicaciones Cultural Colombiana, 1956, pp. 172-173.

364 "Plan de estudios y método para el colegio Pinillos de Mompós, presentado por Eloy Valenzuela". Mompós, 1804. Biblioteca Nacional de Colombia. Sala de Raros y Curiosos, Sección manuscritos No, 385, folio 1. Publicado en HERNANDEZ DE ALBA,G.: Documentos para la historia de la educación en Colombia. 1804-1809. Bogotá, Editorial Kelly, Tomo VII, 1986, pp. 27-96.

${ }^{365}$ El padre General Francisco Javier Vásquez $(-, 1785)$ de origen peruano, fue nombrado general de la orden de los agustinos en 1753. Durante su administración se promovió la reforma de los estudios eclesiásticos. Las constituciones del padre Vásquez no llegaron a publicarse, pero se puso en práctica lo referente a los estudios mediante decretos. Fue de público conocimiento la amistad del padre Vásquez con los ministros "ilustrados" de Carlos III, entre otros Moñino y Roda. Se considera que el padre Vásquez colaboró estrechamente con los representantes de Carlos III, para alcanzar la abolición de la Compañía de Jesús, en CAMPO DEL POZO, Fernando.: El agustinismo y la Retio Studiorum de la Provincia de Nuestra Señora de Gratia en el Nuevo Reino de Granada. San Cristóbal, Universidad Católica del Táchira,1984, p. 60. _. . "Método y profesores de la Universidad de San Nicolás en Bogotá", en Archivo Agustiniano. Vol. LXVIII. No: 186. p. 196. SARRAILH. J.: La España Ilustrada de la Segunda mitad del siglo XVIII. Madrid, Fondo de Cultura Económica, 2a. reimpresión, 1974. pp. 204-700-703. HERR. R.: España y la revolución del siglo XVIII, Editorial Aguilar, 1964, pp. 19-143.

${ }^{366}$ El nuevo plan, que impulsó el padre Vásquez, reemplazaba el escolaticismo por la "filosofía moderna". En la Universidad de San Nicolás de Bari se aplicó mediante la circular del 18 de octubre de 1773. Esta circular la transcribió fray Bautista González, reformador de la Orden de Nuestra Señora de la Gracia. Se debe señalar que entre 1780 y 1790 los estudiantes de las escuelas agustinas de toda España discutían las 
El arzobispo virrey Caballero y Góngora ${ }^{367}$ propone el "estudio de las Ciencias y conocimientos útiles" y el padre José Pérez Calama en su plan de estudios, para la Real Universidad de Santo Tomás de la ciudad de Quito, recomienda enseñar "la literatura más ilustrada, más útil y más sólida". Pero debe señalarse que en la cátedra de Teología, Pérez Calama propugna porque "no se omita el método escolástico" ${ }^{368}$. Este hecho pone de manifiesto el desarrollo de una filosofía ecléctica que en los comienzos se manifestó en los planes de estudio. Por ejemplo en el plan de estudios de filosofía, de Luis Quijano, se señala desde su título que será "un curso ecléctico". Estos planes proponían autores ilustrados y escolásticos, con una filosofía política que dio las bases para el pensamiento revolucionario de la independencia.

Fuera de las aulas universitarias, y en especial a partir de 1779, aparecen publicaciones que critican la educación vigente y propugnan por las "ciencias útiles" y el cultivo de la responsabilidad y el patriotismo. Para la élite criolla "el programa ilustrado debía asumirse en las condiciones sociales y políticas de entonces, como un proyecto de vida" ${ }^{369}$. En Quito, Espejo inicia, en 1779, sus publicaciones con "El nuevo Luciano de Quito y la Ciencia Blancardina". En Santa Fe, en 1783, Mutis asume la dirección de la Expedición Botánica, se publica en Papel Periódico, en 1791, "Avisos de Hebephilo", y, en este mismo año de 1791, Espejo organiza en Quito la Sociedad Patriótica de amigos del País: Escuela de la Concordia y una año después edita el periódico "Primicias de la Cultura de Quito" ${ }^{370 . ~ P o r ~ l o ~ a n t e r i o r ~ e s ~ c l a r o ~ q u e, ~ d e t r a ́ s ~ d e ~ l a s ~ p r o p u e s t a s ~ d e ~ r e f o r m a ~ d e ~ e s t u d i o s, ~}$ existía un trasfondo ideológico mucho más amplio. Tanto en Quito como en Santa Fe un grupo de ilustrados, fuera de las aulas universitarias, impulsaba la nueva filosofía en sus escritos y organizaciones científico-culturales-políticas ${ }^{371}$. Criollos como Caldas, Camilo Torres, Zea, Espejo, Rodríquez, Mejía Lequerica propugnaban por las ciencias aplicadas y exactas en vez de las de carácter meramente especulativo.

proposiciones de los filósofos modernos". Véase en HERR, R.: Op. Cit, p. 143. CAMPO DEL POZO, F.: "Método y profesores de la Universidad de San Nicolás en Bogotá". Op. Cit., p. 196.

${ }^{367}$ El arzobispo-virrey Antonio Caballero y Góngora (1723-1796),natural de Cordoba, España, ejerció el arzobispado y virreinato en el período 1782-1788. Durante su gobierno impulsó la Expedición Botánica, reabrió la cátedra de matemáticas. Se impulsó un plan de estudios con propuesta de universidad pública para la ciudad de Santa Fe en 1787. Véase en BOHORQUEZ CASALLAS, L.: La evolución educativa en Colombia. Bogotá, Publicaciones Cultural Colombiana, 1956, pp. 203 a 205. PEREZ AYALA, J. N.:Antonio Caballero y Góngora, virrey y arzobispo de Santa Fe 1723 - 1796. Bogotá, Imprenta Municipal, 1951.

${ }^{368}$ Al obispo José Pérez de Calama, dominico, le encargó el presidente de la Audiencia de Quito, Luis Muñoz de Guzmán, que elaborara un nuevo plan de estudios el 17 de febrero de 1791, para la universidad oficial, que se había establecido por Real Cédula del 4 de abril de 1786. Calama presentó el nuevo plan en septiembre de 1791. PEREZ CALAMA, José.: Plan de estudios de la Real Universidad de Santo Tomás de Quito. Quito, Palacio Episcopal, 1791__. . Apéndice al Plan de estudios para Real Universidad de Quito, QuitoJniprenta de Raimundo Salazar, 1791__ . : Tercera parte del Plan de estudios de la Real Universidad de Santo Tomás. Imprenta de Raimundo Salazar, 1791 (a este texto se suman unos índices críticos).

${ }^{369}$ ARBOLEDA, Luis Carlos.: "La ciencia y el ideal de ascenso social de los criollos en el virreinato de la Nueva Granada" en Ciencia, Técnica y Estado en la España Ilustrada. Zaragoza, Ministerio de Educación y Ciencia. Secretaría de Estado de Universidades e Investigación. 1988, p. 201.

${ }_{370}$ El periódico Primicias de la Cultura de Quito, apareció en enero de 1792 y dejó de salir el 29 de marzo del mismo año, Espejo solo consigue publicar 7 números. La Sociedad Patriótica de Amigos del País, fue instalada por el obispo José Pérez Calama el 30 de diciembre de 1791. Después de dos años de existencia, la Real Cédula del 11 de noviembre de 1793 desaprobó el establecimiento de esta Sociedad Patriótica. Véase en BEDOYA MARURI Angel Nicanor.: El doctor Francisco Xavier Eugenio de Santa Cruz y Espejo . Quito, The Quito Times, 1982, pp. 102-112.

${ }^{371}$ En Santa Fe se crearon tertulias literarias como la Sociedad Eutropélica dirigida por Manuel del Socorro Rodríguez. El Círculo Literario que coordinaba Nariño, y la Tertulia del Buen Gusto que encauzaba Manuela Santamaría de Manrique. 


\section{La física y las matemáticas, contenidos específicos de la cátedra de filosofía.}

El plan de estudios de la cátedra de filosofía, en general, comprendía tres cursos, y el texto clásico que se seguía era el del padre Goudin. En su orden, los contenidos variaban, pero la norma era enseñar lógica, aritmética, algebra, geometría, trigonometría, física experimental (astronomía, geografía) y ética.

Algo sorprendente es que los ilustrados, a través de esta cátedra de filosofía, lograron introducir la enseñanza de nuevas disciplinas científicas. En 1797, don Miguel Antonio Rodríguez produce dos hechos educativos de singular importancia en la universidad de Quito. Primero, finaliza el curso de física defendiendo, con su alumno Pedro Quiñonez y flores, el sistema copernicano. Segundo, introdujo, en esta cátedra, la enseñanza de la anatomía $^{372}$.

Algunos planes, como el de Eloy Valenzuela, agregan en esta cátedra contenidos de cuentas de comercio, dibujo, electricidad, botánica y "tratados del fuego, aire y agua". Con los anteriores contenidos se pretendía, como señalaba Caballero y Góngora, "sustituir ciencias exactas en lugar de las meramente especulativas" ${ }^{373}$.

El plan de estudios del curso ecléctico de filosofía, que propuso Luis Quijano y Carvajal, introducía en el segundo año la enseñanza de la química moderna, y en el tercer año la física particular, donde se exponía el sistema copernicano y se enseñaba los "tres reinos de la naturaleza" a través de Linneo y Para-du-Phanjas ${ }^{374}$.

Los elementos innovadores, en cuanto a los contenidos, los encontramos en las matemáticas unidos a la física experimental, al enseñarse la "filosofía natural newtoniana", porque ésta significaba un giro copernicano respecto a la concepción del mundo tradicional imperante. Además, Newton juega un papel fundamental en la nueva filosofía con su riguroso método donde no prima la deducción sino el análisis.

Esta filosofía natural newtoniana la expone y enseña en la ciudad de Santa Fe de Bogotá, por primera vez, José Celestino Mutis ${ }^{375}$, quien señala que el objeto de esta filosofía

\footnotetext{
${ }^{372}$ PALADINES ESCUDERO, Carlos: "Estudio introductorio". Op. Cit., pp.51-83.

373 "La instrucción pública en el virrey Caballero y Góngora".Santa Fe, 20 febrero, 1789, en HERNANDEZ DE ALBA, G .: Documentos para la Historia de la educación en Colombia, 1777-1800. Bogotá, Editorial Kelly. Tomo V, 1983, p. 168.

${ }^{374}$ QUIJANO Y CARVAJAL, Luis.: "Plan de estudios del curso eclético de filosofía moderna para el real colegio de San Fernando, Quito, 1803", en Boletín de la Academia Nacional de Historia, vol. VI, Quito, Imprenta de la Universidad Central, 1923, pp.129 -137. Quijano y Carvajal, era natural de la ciudad de Popayán, se había graduado en la Universidad de Santo Tomás de Aquino. Fue abogado de la Real Audiencia, en 1799 y participé como senador en la Junta Suprema Gubernativa del Reino de Quito, en 1809. La anterior Junta reemplazó a la Real Audiencia derrocada el 10 de agosto.

375 Juan Manuel Pacheco señala que hacia 1757, en la universidad Javeriana de la ciudad de Santa Fe, el profesor de filosofía ya enseñaba las teorías de Newton y Huyghens. Sin embargo, los contemporáneos de Mutis y él mismo se consideraba como el primero que dio tales estudios de matemáticas, en la ciudad de Santa Fe. PACHECO, J,M.: La llustración en el Nuevo Reino. Caracas, Universidad Católica Andrés Bello, 1975, p. 10. Debemos señalar que en el virreinato de la Nueva Granada las teorías de Copérnico y Newton entran por primera vez a través de los jesuitas en la Universidad Gregoriana de Quito. Hacia 1744 el padre Magnin defiende el sistema copernicano en su obra "Milliet en armonía con Descartes o Descartes reformado". En 1747 Magnin remite por segunda vez este texto a Europa. Véase en PALADINES ESCUDERO, Carlos.: Op. Cit., pp. 38-39. Posteriormente el padre Francisco Aguilar en 1751 lo enseña y, en 1761, el padre Juan de Hospital con su alumno Carvajal realizan públicas conclusiones sobre Copérnico. 
natural es "describir los fenómenos de la naturaleza, descubrir sus causas, exponer sus relaciones y hacer descubrimientos sobre toda la constitución y orden del Universo" ${ }^{376 .}$

\section{La filosofía de la ilustración se contrapone a la escolástica en la cátedra de filosofía.}

Para entender la orientación que se dio a la cátedra de filosofía en estos planes ilustrados, debemos partir de la mentalidad de sus autores, casi todos ellos clérigos, excepto Moreno y Escandón y Luis Quijano y Carvajal, pertenecientes incluso a la jerarquía eclesiástica.

Nos encontramos, de tal manera, con unos hombres influidos por la filosofía ilustrada, la oficial de la época, que tratan de plantear soluciones más racionales y objetivas a los problemas de la actividad económica y humana, pero cuidándose mucho de no chocar con la ortodoxia religiosa oficial. Como es sabido, escribir en el Siglo XVIII, especialmente si se era consciente de ser heterodoxo, aunque sólo fuese mínimamente, era pensar en la censura y en la represión inquisitorial.

Hay, sin embargo, dos aspectos de esos ilustrados que nos interesa resaltar. Por un lado, su mentalidad religiosa y, por otro, su actitud ante la ciencia.

Aunque no pueda llegar a afirmarse que estos ilustrados fueran deístas, lo cierto es que algunos se aproximaron a un primer grado de deísmo, al aplicar la razón a los principios religiosos $^{377}$. Quizá el concepto más claro lo da el historiador Juan Manuel Pacheco al afirmar que el aspecto religioso de la iluminación fue la "religión natural", basada en la autonomía de la razón, en la que no tenían cabida las "religiones reveladas" 378.

En el citado plan del fiscal Moreno y Escandón se inicia un ataque frontal a la escolástica, al considerarse que no se puede "prescribir un acertado método" si no se erradica el escolasticismo. Señala Moreno que el "escolasticismo, como el apego a escuelas, es tan tenaz y autorizado que puede inducir desconfianza de la victoria" ${ }^{379}$.

Moreno, contraponiendo al método escolástico, al que atribuye el "origen del atraso y desórdenes literarios" 380 , desarrolla el método de la observación y la experiencia, especialmente en el estudio de las ciencias naturales. Pero para erradicar la "pestilente" escolástica el paso decisivo debía ser "imprimir en el corazón de los estudiantes el uso de la razón”, porque, según él, la razón era el instrumento de formación y entrenamiento", era

\footnotetext{
${ }^{376}$ DOCUMENTOS :: Mutis y la Expedición Botánica. Bogotá, El Ancora Editores, 1983, pp. 33-34. Luis Carlos Arboleda ha localizado en el Archivo del Jardín Botánico de Madrid la traducción que realizó Mutis, de la Principia de Newton, al castellano. En este trabajo Arboleda realiza un análisis historiográfico del manuscrito, del discurso histórico-epistemológico y del contexto socio-cultural de la época. Véase en ARBOLEDA, Luis Carlos.: Newton en la Nueva Granada. Elementos inéditos sobre los orígenes de nuestra cultura científica. Cali, Universidad del Valle, julio de 1990.

377 HERRERO, J .: Los orígenes del pensamiento reaccionario español. Madrid, Editorial Cuadernos para el Diálogo, 1973, p. 93. Considera Herrero que "el primer grado del deísmo es aplicar la razón a los principios religiosos; en el segundo grado, la razón reemplaza a la religión y la religión revelada es reemplazada por la religión natural; y el tercer grado es el realmente deísta o libertino". Véase una amplia explicación sobre la asimilación del deísmo en José Celestino Mutis en SOTO ARANGO, D.: Mutis filósofo y educador. Bogotá, Universidad Pedagógica Nacional, 1989, pp. 3-9.

${ }^{378}$ PACHECO, J.M .: La llustración en el Nuevo Reino. Op. Cit., p. 6.

379 "Plan de estudios del fiscal Moreno y Escandón de 1774". Doc. Cit., folio 1. (numeración nuestra).

380 Ibídem., folio 2.
} 
el rasgo distintivo de la elección y, en cualquier caso, "la elección debía ser libre y gobernada por la razón, sin formar empeño en sostener determinado dictamen" ${ }^{381}$.

Moreno, al desarrollar estas nuevas ideas en su plan, unía la razón con el estudio de la naturaleza. A esta última, la consideraba como "el origen de donde saldría el influjo universal para el fomento de la agricultura, de las artes y del comercio de todo el Reino, cuya ignorancia lo tiene reducido al mayor abatimiento". Para la consecución de lo anterior, Moreno insiste en la necesidad de "enseñar la geografía, la historia natural, las observaciones meteorológicas, la rama de agricultura y el conocimiento desde sus preciosos minerales. Para que los curas puedan dirigir a los demás hombres en sus parroquias" ${ }^{382}$ y poder lograr el "feliz principio de la llustración" que sería el "anuncio y fundamento de prosperidad" ${ }^{383}$.

Podemos señalar que Moreno se proponía formar un nuevo tipo de individuo, que fuese agente activo de progreso y que cambiara la mentalidad que se tenía en el terreno económico y cultural.

Pero, como puede suponerse, en tanto estos nuevos hombres no podían seguir formándose bajo el método escolástico, se hacía necesario un cambio ideológico que, para Moreno, al igual que para los ilustrados españoles, se centraba en el desarrollo económico y educativo; de ahí la necesidad de reformar los planes de estudio.

Así, el plan educativo de Moreno propone un nuevo método, basado en la "observación y la experiencia". Este método formaría el "juicio" que luego se dirigiría al estudio de las matemáticas que, en su opinión, eran las que facilitaban la entrada a las demás ciencias" 384

Pero el paso decisivo para conseguir lo anterior estaba en rechazar la escolástica. Este rechazo no sólo sería en la especulación filosófico-teológica ${ }^{385}$, sino también en el contenido y forma de la enseñanza ${ }^{386}$.

A la conocida crítica que se le hace a Moreno por no haber planteado cambios en los contenidos consideramos que, en cualquier caso, al introducir nuevos autores que frente al punto de vista de la "verdad como revelación"o la "verdad como autoridad", contrapusieran la "explicación de la realidad", este solo hecho llevaba a plantear una nueva norma de conocimiento de los contenidos. Por muy paradójico que parezca en un principio, estos conocimientos, conservaron las denominaciones de las carreras y

\footnotetext{
381 Ibídem., folio 2.

382 Ibídem., folio 7.

383 Ibídem., folio 1.

${ }^{384}$ Señala el fiscal Moreno que de la observación y la experiencia se "deducen unos razonamientos que si son ajustados a las reglas de una buena lógica, y dirigidos por los preceptos elementales de las matemáticas van conduciendo con mucha seguridad en el conocimiento de la naturaleza". Ibídem., folio 7.

${ }^{385}$ Dice Moreno que "las cuestiones estériles y puramente especulativas no dejan jugo en el corazón del hombre". Ibídem., folio 9.

${ }^{386}$ El método escolástico busca su enseñanza en las "siete artes liberales", divididas en el trivium (gramática, dialéctica, retórica) y el cuadrivium (aritmética, geometría, música, astrología, más tarde astronomía"). Y las formas fundamentales de enseñanza eran: La lectio (que era el comentario de un libro por parte del maestro académico) y la disputatio (era el diálogo entre maestros y discípulos, en que se sacaban a colación argumentos en pro y contra de una determinada tesis). Véase en HIRSCHBERGER, J.: Historia de la filosofía. Barcelona, Editorial Herder; Tomo 1, 1954. pp. 329-330. RIVAS SACCONI, J.M. EI latín en Colombia. Bogotá, Instituto Caro y Cuervo, 1949, pp. 54-64. Unido a la lectio estaba el dictado a mamotretos que eran "las notas tomadas bajo el dictado del catedrático".
} 
asignaturas. Pero no por esto dejamos de estar de acuerdo con el planteamiento de Jaramillo Uribe, según el cual "la línea divisoria entre el pensamiento moderno estaba en el método, más que en el contenido mismo de las ideas" ${ }^{387}$.

El fiscal Moreno planteaba que se utilizaran autores que "explicaran la realidad" y defendieran "el derecho a la crítica científica de cuestiones juzgadas hasta entonces de la exclusiva competencia de la religión" ${ }^{388}$ Por este hecho no se le puede acusar de atacar la religión católica sino, por el contrario, al igual que Mutis, lo que se proponía era elevar la cultura religiosa. La anterior postura, es posible que reflejara más si, como puede suponerse, esta postura obedecía a ese pensamiento ilustrado español que, como el alemán, "más que arrancar a la religión derechos en favor de la razón, busca la aveniencia entre el saber y la fe, entre la ciencia y la religión" ${ }^{389}$.

En cuanto a los otros planes de estudio que siguieron la misma línea de pensamiento ilustrado y de oposición a la escolástica, se encuentra el de Caballero y Góngora, quien contrapuso a la escolástica una mayor gama de autores ilustrados. Además el de Eloy Valenzuela, plan que por sí solo es una confrontación directa con la escolástica, al pregonar la enseñanza de las ciencias naturales y atacar la escolástica de Goudin, debido a que, en su opinión, "ésta atolondra, enmaraña y confunde, y así no conviene mucho el esmero en estudiarla" 390 .

Por su parte, el padre Francisco Javier Vásquez, en su reforma de estudios, aplicada mediante circulares en la Universidad de San Nicolás de Barí391, señala que "se destierre, que del todo se quite de las escuelas aquella filosofía y teología peripatéticas llenas de cuestiones inútiles y cavilosas, que no sirven para otra cosa que para perder el tiempo inútilmente, y que se enseñe una filosofía útil y provechosa, capaz de habilitar a los estudiantes para el estudio fructuoso de las demás facultades y hallar la verdad, que es el fin a que todos aspiran" ${ }^{392}$.

El nuevo método, que combatía la escolástica, parece que se empezó a aplicar en esta Universidad de San Nicolás de Bari a partir del mes de junio de 1776, cuando se reorganizaron los estudios eclesiásticos superiores en los conventos de los agustinos calzados de Cartagena y Santa Fe. En esta última ciudad, fue elegido moderador de la cátedra de filosofía el padre Diego Francisco Padilla ${ }^{393}$.

387 JARAMILLO URIBE, J.: El pensamiento colombiano en el siglo XIX. Bogotá, Editorial Temis, 3a. edición, 1982 , p. 330.

${ }^{388}$ IOVCUK, M, y otros.: Historia de la filosofía. Moscú, Editorial Progreso, Tomo 1., 1978, p. 261

389 Ibídem., p.261.

390 "Plan de Estudios de Eloy Valenzuela. I804".Doc. Cit. folio $17 \mathrm{v}$.

${ }^{391}$ La Universidad de San Nicolás de Bari obtuvo la Bula del 24 de abril de 1694, que le daba facultad para fundar universidad y conferir grados académicos en filosofía y teología a los religiosos agustinos de la Provincia de la Gracia. En 1697 comenzó el curso académico, pero sólo hasta el 22 de abril de 1703 se le otorgó el pase regio. Inicialmente la universidad funcionó en la misma instalación locativa del convento agustiniano. Posteriormente, de 1739 a 1775 funcionó en edificio aparte con el Colegio de San Miguel. En 1775 el visitador -reformado Juan Bautista Gonzalez cerró el colegio donando el edificio para el seminario conciliar; la universidad siguió funcionando a pesar del cierre del colegio hasta 1861, siendo su último rector Felipe Bernal. Véase en CAMPO DEL POZO, F,: El agustinismo y la Ratio Studiorum de la Provincia de Nuestra Señora de Gracia en el Nuevo Reino de Granada. Op. Cit., pp. 49-57-82 :"Método y profesores de la Universidad de San Nicolás". Doc. Cit., pp. 200-201.

392 "Circular de Fray Bautista González, reformador de la orden agustiniana en la Provincia de la Gracia, sobre la reforma de estudios del Padre Vásquez la que debía aplicarse en la Universidad de San Nicolás de Bari". Santa Fe 18 de octubre de 1773. Archivo Histórico Nacional de Colombia. (A.H.N.C.). Sección Colonia, FondoConventos, Tomo 47, folio $92 \mathrm{v}$.

${ }^{393}$ El criollo Diego Francisco Padilla, agustino calzado, tuvo a su cargo la cátedra de filosofía, desde 1776 hasta 1782, en la universidad de San Nicolás de Bari. Allí impuso el nuevo sistema, admitiendo la filosofía Digitalizado por RED ACADEMICA 
En la orden de aplicación del plan de estudio de filosofía, propuesto por Luis Quijano y Carvajal, se señala por parte del presidente de la Audiencia, don Luis Francisco Héctor, Barón de Carondelet, que "no será regular que se dictase la peripatética" ${ }^{394}$.

En general, podemos decir que el modo de filosofar del método escolástico se sustituyó en los planes ilustrados por la observación y el estudio de la naturaleza y si bien estos planteamientos, vistos desde ahora puedan parecer elementales, en su momento fueron francamente novedosos y progresistas. No obstante, el alcance práctico y sus objetivos no pasaron del papel. Pero no se trata de analizar ahora este aspecto del problema, porque consideramos que estas propuestas representan una faceta más de estos ilustrados. La repercusión de estos planes tiene que estudiarse dentro del contexto de la actividad científico-cultural que desarrollaba cada uno de estos individuos. Por otra parte, debemos señalar que con el plan de Moreno se consiguió introducir una mentalidad más liberal en algunos miembros de la élite criolla que estudiaban en los colegios del Rosario y San Bartolomé. La nueva filosofía contó con la aprobación de Vergara, Vásquez y Vallecilla en el Colegio del Rosario; y en la universidad de San Nicolás, con Padilla. A través de las cátedras de matemáticas y filosofía estos maestros asimilaron el nuevo método experimental, basado en Newton, para contraponerse a la filosofía escolástica ${ }^{395}$.

Las nuevas ideas y la lucha contra la escolástica, iniciadas por Moreno, Mutis y Padilla entre otros, se abrieron paso con firmeza, mediante el apoyo a los virreyes, pero no sin resistencia por parte del sector tradicional en especial de Santa Fe. A pesar de la oposición y las polémicas que se suscitaron, "la filosofía moderna" se propagó entre "la élite criolla", creando en esta naciente generación una dimensión filosófico-política diferente.

Algunos ilustrados criollos de finales del siglo XV1I1 se caracterizaron por su posición política. La anterior actitud se manifestó en la vinculación que se dio en las diferentes actividades del proceso revolucionario de la independencia. En efecto, hay varios hechos que, según puede establecerse por algunos documentos, indican esta participación política. Igualmente se dio, en algunos casos, una estrecha relación entre los ilustrados santafereños y quiteños. Como es bien sabido, en el caso de Eugenio Espejo se conoce su vinculación por carta con Mutis y posteriormente su relación directa con éste y el grupo de la Expedición Botánica de Santa Fe, durante su estadía en esa ciudad, en 1789. Unos años más tarde Espajo organiza la Sociedad Patriótica de Amigos del País y luego publica el periódico Primicias de la Cultura de Quito. El análisis del fenómeno político colonial, en relación a una generalización de la actividad de los criollos ilustrados, es difícil de establecer porque cada uno representaba un mundo cultural y de intereses económicos diferentes. Sin embargo, puede afirmarse, por ciertas actividades que desarrollaron

moderna según el plan trazado por el padre General Vásquez. En el lo. enseñó la lógica; en el segundo, la física general y particular, que comprendía también la metafísica; y en el tercero, un curso íntegro de enea en tres partes, de acuerdo con la nueva metodología. En 1786 asistió al capítulo general y pasó por Francia, Italia y España donde consiguió varios libros de la filosofía enciclopedista, para la Universidad de San Nicolás de Bari. En 1788 fue nombrado Regente de Estudios de la universidad y junto con el rector padre Bernardo Londoño reorganizaron los estudios de Filosofía con un examen de las ideas de Descartes, Bacon, Newton, Locke, Montesquieu, Pascal y otros autores. CAMPO DEL POZO, Fernando.: El agustinismo y la Ratio Studiorum de la Provincia de Nuestra Señora de Gracia en el Nuevo Reino de Granada. Op. Cit., p. 66-70-71.

${ }^{394}$ QUIJANO Y CARVAJAL, Luis.: Op. Cit., p.131.

${ }^{395}$ En la Universidad de San Nicolás de Bari a la cátedra de filosofía, hacia 1788, "la frecuentaban extraños y laicos" y hacia 1800 se creó la cátedra de matemáticas, donde se enseñaba a Newton y Copérnico" CAMPO DEL POZO, F.: El agustinismo y la Ratio Studiorum de la Provincia de Nuestra Señora de Gracia en el Nuevo Reino de Granada. Op. Cit., p. 71

Digitalizado por RED ACADEMICA 
algunos criollos quiteños-santafereños, que entre ellos se dió una estrecha relación político-cultural $^{396}$.

\section{El eclecticismo se impone al espíritu de partido.}

Para abrir paso a las nuevas ideas, el fiscal Moreno las sustentó en los criterios y mandatos reales, pero aún así, la resistencia de los sectores tradicionales y clericales lo llevó a emprender una dura batalla por uno de los aspectos que suscito más viva polémica, como fue su postura contraria al "espíritu de partido".

Como puede suponerse, los dominicos y el rector del Colegio del Rosario encabezaron la oposición contra Moreno porque, precisamente, las instituciones que representaban tenían constituciones que determinaban que sólo se seguiría la doctrina de Santo Tomás. Sin embargo, pese a la polémica y las objeciones, el fiscal transcribe en su plan que los justísimos deseos del católico monarca eran extinguir radicalmente todo espíritu de partido, "renunciando a la perjudicial máxima de seguir una escuela jurada". Apoyándose en lo anterior, Moreno consideraba que debía excluirse del plan "la literal explicación de los sentenciarios de los jefes escolásticos y sus difusas obras"397.

Es curioso, el comportamiento diferente que adopta la comunidad de los dominicos en Santa Fe y Quito. En la primera ciudad, Santa Fe, es posible que estos religiosos vieran sus intereses educativos y de poder político amenazados con la propuesta de Universidad Pública que proponía Moreno y Escandón, y por este motivo se enfrentaron en la más dura polémica con el fiscal y Mutis. En cambio, en Quito, la nueva universidad pública creada por la Junta de Temporalidades, el 23 de agosto de 1776, producto de la fusión del seminario de San Luis y de la universidad Santo Tomás ${ }^{398}$, no tiene resistencia en su fundación por parte de los dominicos. Si bien es cierto que ellos entablaron una polémica posterior por los privilegios económicos ${ }^{399}$, la nueva universidad pública garantizó a la comunidad de Santo Domingo "conservarle los privilegios correspondientes como primitivos fundadores". Los dominicos, cuando inicia labores en 1788 la nueva universidad, regentaron las cátedras de filosofía, teología y gramática en propiedad ${ }^{400}$.

\footnotetext{
${ }^{396}$ Además de Espejo podemos señalar otros casos como el de José Mejía Lequerica. que le dedica un acto académico a Mutis en 1803. Y la relación del mismo Mejía con Caldas a partir de 1801. Por citar otro caso tenemos el de Ante, discípulo de Espejo, que proyectó liberar a Nariño de su cautiverio. Véase en PALADINES ESCUDERO,

C.: Op. Cit., pp. 53, 54 y 60.

397 "Plan de estudios del fiscal Moreno 1774". Doc. Cit. f. 11 (numeración y subrayado nuestro).

${ }^{398}$ En Quito surgen tres universidades regentadas por órdenes religiosas. La primera universidad que se creó fue la de San Fulgencio, por los agustinos calzados, en 1586. A esta universidad se le prohíbe otorgar grados en 1786, por Real Cédula de Carlos 111. Los jesuitas, por su parte, regentaban el colegio de San Luis desde 1594 y en 1622 se les otorga la Real Cédula para crear la universidad de San Gregorio Magno. Esta universidad se clausuró por Orden Real del 9 de julio de 1769. La comunidad de Santo Domingo dirigió el Real Colegio de San Femando (1693) y la universidad Santo Tomás desde 1688 hasta 1776 cuando se erigió la universidad pública. Véase en RODRIGUEZ CRUZ, Agueda.: Historia de las Universidades Hispanoamericanas. Bogotá, Instituto Caro y Cuervo, 1973, Tomo I, pp. 415, 503 y 547.

${ }^{399}$ No deja de ser curiosa la polémica que entablan los dominicos ante la Corte para que se les restituyera las rentas y posesiones de la universidad Santo Tomás. Este debate se cierra a su favor en las prerrogativas que se le conceden al Colegio San Femando en el año de 1800. Véase la documentación, en Archivo General de Indias. Audiencia de Quito, legajos 196, 402.

${ }^{400}$ Está por estudiar el hecho de que la Universidad Santo Tomás haya otorgado grados en el período $1770-$ 1788. Por la información que tenemos, hasta el momento, en la época que va de 1776 a 1788 la universidad de los dominicos estaba cerrada y la universidad pública aún no iniciaba labores académicas. Véase ZUNIGA, Neptalí.: Colección documental de la universidad Central del Ecuador. Quito. Universidad Central de Ecuador, Instituto de Investigaciones Históricas, Vol. I, 1967, p. XXIII. LOZANO CABRERA, M.: "Origen y 
Igual situación se presenta con la reforma de estudios del obispo José Pérez Calama, en 1791, que aunque no se aplicó el plan, en el proyecto le garantiza a la comunidad de Santo Domingo regentar algunas cátedras ${ }^{401}$.

Ya en el siglo XIX, en 1803 aceptan los dominicos, sin reserva, enseñar la nueva filosofía y eliminar la peripátetica en el colegio de San Fernando, según lo dispuesto por la reforma de estudios que había ordenado el presidente de audiencia. Situación diferente tiene que afrontar Moreno en Santa Fe. El plan de estudios que presentó, el fiscal lo justificó en los deseos reales y en la nueva realidad cultural que se vivía en Europa.

Así lo describe una vez más Moreno en su plan: "los planes de estudio formados para el arreglo de las universidades de España, uniformemente conspiran en que se destierre todo el espíritu de facción y partido y que para ellos no se obligue a los discípulos a seguir determinado autor ni escuela, no porque deje de tomarse alguno por modelo, sino porque no se forme partido y empeño"402.

Quizá lo más relevante de la cita anterior, además del ataque al espíritu de partido, sea su manifiesto eclecticismo, que pregona en su método y que lo ayudaría a combatir la escolástica y de la misma forma a desarrollar el libre raciocinio de la juventud neogranadina.

El fiscal, haciendo uso del eclecticismo, propone formar alumnos que tengan la libre opción de estudiar autores diversos para que de esta manera se formen la razón y el juicio sin "abrazar partido".

Para conseguir su objetivo de "desterrar el espíritu de partido", Moreno no sólo entra en el tren del eclecticismo, sino que también propone, como lo señalamos anteriormente, el estudio de las ciencias naturales, porque era allí también donde se "elevaba el espíritu, se formaba el mejor juicio", desterrando el "espíritu de facción", que tantos males acarreaba a la formación intelectual de la juventud.

En igual línea de pensamiento encontramos a Eloy Valenzuela, quien con su filosofía ilustrada consideraba que era indispensable desterrar el "espíritu de partido", porque era el origen del atraso y la causa del no avance científico del país. Al respecto dice Valenzuela, "será perjudicial a la enseñanza fomentar en los jóvenes espíritu de partido... seguir determinada escuela o partido... que han perjudicado a las ciencias en España" ${ }^{403}$.

En general, podemos afirmar que el "desterrar el espíritu de partido es una de las características de los ilustrados neogranadinos, pues veían en el "espíritu de facción" un gran obstáculo para desarrollar el cambio ideológico y económico que se proponían conseguir.

\section{Contra el dictado, lectura directa del texto.}

\footnotetext{
desarrollo de la universidad ecuatoriana', en Revista Filosofía, Letras y Ciencias de la Educación. Quito, universidad Central del Ecuador, No.8, año III, octubre de 1950, pp.150- 151. PEREZ GUERRERO, Alfredo.: Biografía y Símbolo de la Universidad de Quito. Quito, Anales de la universidad Central, p.8.

${ }^{401}$ PEREZ CALAMA, José (obispo).: "Plan de estudios de la Real Universidad de Quito' en Boletín de la biblioteca Nacional del Ecuador. Quito, Talleres Tipográficos Nacionales, No. 1, octubre de 1920, pp. 66-84.

402 Ibídem., f.19 (numeración y subrayado nuestro)

403 "Plan de estudios de Eloy Valenzuela, 1804" Doc. Cit, f. 17. 
La primera regla general que propone Moreno en la enseñanza es "desterrar radicalmente de ambos colegios la nociva costumbre de dictar los maestros las lecciones, haciéndolas escribir a sus discípulos"404, método que utilizaba la escolástica para transmitir sus conocimientos.

Al respecto señala Rivas Sacconi: "era costumbre en América como en Europa que cada profesor explicase su propio curso; de suerte que los alumnos tenían obligación de tomar atenta nota de las lecciones para reconstruirlas en la forma más completa posible en sus cuadernos. La mayoría de veces el lector o maestro dictaba la lección" 405. A estos dictados se les llama también mamotretos por ser las "notas tomadas bajo el dictado del catedrático" ${ }^{406}$. Comenta Rivas que la clase se transformaba prácticamente en un dictado, donde la explicación ocupaba un tiempo reducido, "siendo los mamotretos, con demasiada frecuencia, exposiciones elementales y mediocres" 407

En el plan de Peréz Calama se realiza una fuerte crítica a la forma de enseñanza y a la utilización de los textos. Según Calama, el catedrático "señala un discípulo para que diga la conferencia de memoria sensitiva. Si no la sabe el joven, le corrige y reprende con aspereza. Señala a los otros dos o tres para los párrafos siguientes. Concluida esta relación de papagayazo, comienza el tal maestro a formar su explicación con un lenguaje mixto de varios idiomas; pues ni es latino, ni es castellano". Continúa en su exposición el obispo, señalando que "lo peor es que muchos tomaban de los autores lo menos útil y dejaban lo más importante" ${ }^{" 408}$.

Por otra parte, Luis Quijano, si bien no cuestiona abiertamente en el plan los estudios impartidos en la época, sus planteamientos son por sí solos una homilía a la filosofía ilustrada. Quizá con suma perspicacia se percató que para introducir la "filosofía moderna", en el claustro de los dominicos, no debía cuestionar abiertamente la escolástica. Posiblemente consideró que debía limitarse, en el texto oficial, a desarrollar los contenidos que aseguraran la enseñanza con los textos de autores ilustrados ${ }^{409}$.

Dentro de esta mentalidad reformista y a cambio de este "nocivo" método del dictado, Moreno proponía la lectura directa del texto "eligiendo un autor que sin pecar en la difusión ni abrazar partido, sirva de modelo para que los maestros de este Reino formen a competencia un curso" ${ }^{\prime 10}$

\footnotetext{
404 "Plan de estudios del fiscal Moreno, 1774" Dc. Cit., f. 17 (numeración nuestra).

${ }^{405}$ RIVAS SACCONI, J.M.: El latín en Colombia. Op. Cit., p. 89.

406 lbídem., p. 64.

407 Ibídem., p. 90.

408 PEREZ CALAMA, J. "Plan de estudios de la Real Universidad de Quito". Op. Cit., p.70.

409 El doctor Luis Quijano y Carvajal propone que, para el primer año, la Historia de la Filosofía se enseñara a través de Heinecio, Jacquier y Genovesi. En el segundo año, los contenidos versan sobre los elementos de matemática y física general. El curso se organiza en dos grandes temáticas: la física general y la química moderna. Los autores a seguir son Jacquier, José Cocquete, Lavoyisier y Fourcroy. El tercer año, titulado física particular, lo organiza en tres grandes temáticas: a) Sistema del mundo y la electricidad, por autores como Jacquier y el Docto Mínimo que expone el sistema copernicano, b) los tres Reynos, con obras de Linneo y Para-du-Phanjas y c) matemáticas, historia natural y física con los textos de Bails, Besout, Fond, Brison, Musskenbroek y S'Gravesande. Véase en QUIJANO Y CARVAJAL, L.: Op.Cit., pp.131 a 136.

410 "Plan de Estudios del fiscal Moreno, 1774". Doc. Cit. f. 12 (numeración nuestra). Al respecto decía Nagáns en 1754 que "libros y maestros buenos son necesarios para la enseñanza pública. Sin buenos libros no pueden ayer buenos maestros; sin buenos maestros, no pueden ayer aventajados discípulos. En las Universidades de España. que son los seminarios de los hombres sabios, no hay elección de buenos libros, porque los maestros no los conocen o no tienen autoridad para introducirlos", citado por ALVAREZ DE MORALES, A.: Op. Cit., p. 103.
} 
Entendía el fiscal Moreno que era con el método como se podía garantizar la difusión de las ideas ilustradas; por tal motivo insiste en liberar a los estudiantes de la "perniciosa molestia de escribir"411.

Al respecto, anota Jaramillo Uribe que "su espíritu de cautela y ortodoxia no disimulaba el anhelo de ver el pensamiento liberado del método dogmático, del criterio de autoridad y de la especulación verbalista" ${ }^{\prime 12}$.

Debemos señalar que cuando Moreno dice que debe estudiarse a partir de las fuentes no se refiere al texto de la fuente original, sino al libro que el método recomienda en su plan; por ejemplo, para el estudio de Santo Tomás y Escoto, debía leerse el texto de Juan Bautista Duhamel, autor que ya se había propuesto en la Universidad de Cervera ${ }^{413}$ para sustituir el curso de Philosophia Tomista de Goudin ${ }^{414}$, Es decir, no se daría la escolástica tomística; se enseñaría el texto de philosophia vetus et nova de Duhamel, obra catalogada de "especulativa y experimental", cuyo autor era caracterizado de "ecléctico y matizado de escepticismo humanista" ${ }^{415}$.

A Goudin le contraponen, en el plan Sevilla, a Melchor Cano, cuyos libros igualmente se recomiendan en el virreinato de la Nueva Granada dentro del plan de Moreno y Escandón. Recordemos que Melchor Cano se caracterizó no por ser un acérrimo antiescolástico", sino un "moderado" en la interpretación y seguimiento de la Summa Theologica de Santo Tomás ${ }^{416}$ por lo tanto, no puede afirmarse que Moreno se opusiese al estudio de Santo Tomás; por el contrario, al ser su método ecléctico, se enseñaba también la metafísica, pero a través de autores no escolásticos, "moderados" como era el caso de Melchor Cano.

Entre los autores de marcada tendencia antiescolástica recomendados tanto en el plan de estudios de la Universidad de Sevilla, propuesto por Olavide, como en el plan de Moreno, para la cátedra de filosofía, se encuentra al franciscano Fortunato de Brescia (1.714-1754). Este autór se caracterizó por ser "acérrimo enemigo de la escolástica, la combatto siempre que pudo y cultivó con ardor las ciencias exactas". Además su libro

\footnotetext{
${ }^{411}$ Ibídem., f. 10.

412 JARAMILLO URIBE, J.:El pensamiento colombiano en el siglo XIX. Op. Cit., p.330.

${ }^{413}$ Las universidades de Alcalá y Cervera se acogieron a la orden del Real Consejo de 1770, de formar un nuevo "plan de estudios metódico y remozado, reforzando el estudio de las matemáticas y de la física experimental". Véase en HIRSCHBERGER, J.: Historia de la filosofía. Barcelona, Editorial Herder, Tomo 2,1956, p. 467.

414 Antonio Goudin ( 1639-1695), padre dominico, "pertenece a los escolásticos tradicionales de la decadencia de aquellos que, frente a la filosofía moderna, siguen considerando la física como parte integrante de la filosofía, pasan por alto o impugnan las nuevas teorías científicas y filosóficas y reproducen en sus tratados las doctrinas escolásticas aunque más sistematizadas y ya no en forma de comentarios de Aristóteles". Su principal obra Philosophia Thomistica Juxta Inconcussa Tutissimaque Divi Thomas Dogmata, quator Tomis comprenhensa, se explicaba en tres años, en el primero, toda la lógica, en el segundo, la física general y los tratados del cielo, del mundo y de la generación y corrupción, en el tercero el tratado del alma y la metafísica", en SALAZAR, J.A.: Los estudios eclesiásticos superiores en el Nuevo Reino de Granada 1563-1810. Madrid, Consejo Superior de Investigaciones científicas 1946, pp. 178-179 y en HIRSCHBERGER, J.: Historia de la filosofía, tomo I, Op. Cit., pp. 519-20.

${ }^{415}$ HIRSCHBERGER, J.: Historia de la filosofía. Tomo 2, Op. Cit., p. 467.

${ }^{416}$ MELCHOR CANO (+ 1560, "discípulo e intérprete del método de Victoria, de su sentido humanista, buen decir y ensanchamiento de las bases teológicas con una metódica utilización de las fuentes positivas", en HIRSCHBERGER. J.: Historia de la filosofía, Tomo I. Op. Cit., pp. 602-605.
} 
estaba "compuesto del texto de Wolff, Newton, Malpighi, Boerhaave, Leibnitz y los más recomendables y conocidos por grandes en la república literaria""17.

Pero, sin lugar a dudas, el autor que marca el paso hacia el estudio de las ciencias naturales es Christian Wolff (1679 - 1754), perteneciente a la segunda generación de la ilustración alemana. Sus teorías encajan perfectamente en la mentalidad del fiscal Moreno y de Eloy Valenzuela, porque no disocia el "saber de la fe metafísica y religión, concretamente de la religión cristiana" ${ }^{\prime 18}$. Es decir, pertenece al grupo que propugna por el avance científico, pero defendiendo la religión cristiana. A Wolff se le considera seguidor de Leibnitz, quien "tampoco vio oposición alguna entre la razón y la fe. Igualmente se considera que la filosofía racionalista de Wolff, basada en el método matemático, "osciló permanentemente entre las ideas de Descartes y las de Leibnitz, precisamente por querer aplicar ese método a la filosofía, un campo del pensamiento en donde las especulaciones no son puramente racionales sino también experimentales" ${ }^{419}$.

Parece claro que las teorías de Wolff no sólo quedaron consignadas en el plan de Moreno y en el de Eloy Valenzuela, sino que también se enseñaron e impulsaron desde la cátedra de matemáticas de Mutis. Criterios como la "libertad filosófica" o que las "reglas del método filosófico deben ser idénticas a las del método matemático" ${ }^{420}$ sirvieron de base para la enseñanza de las teorías de Newton y Copérnico, que se impartieron en el virreinato a pesar de las controversias que propiciaron los dominicos y los rectores del colegio del Rosario.

Ciertamente, Wolff es uno de los autores que más se cita en los planes ilustrados de este virreinato, pero, no obstante, es Isaac Newton (1.662-1.727) quien marca la pauta en el cambio de método en estos planes ilustrados.

La introducción y defensa del sistema filosófico de Newton en el virreinato de la Nueva Granada puede ser considerada como una de las máximas aportaciones de José Celestino Mutis (1732-1808), porque expone y enseña en Nuevo Mundo una filosofía que significaba un giro copernicano respecto a la concepción del mundo tradicional imperante. Mutis asimiló a Newton de una manera particular, él elaboró las lecciones para sus alumnos y lo explicó a su manera. Si bien sabemos que Feijoo confesó en cartas eruditas II, XXIII, "la imposibilidad que halló en explicar al público español, ni aún superficialmente, el sistema Newtoniano", decía "yo no tengo de Newton sino las Instituciones de su Philosophia, que compiló S'Gravesande, el cual se abstiene en entrar en aquellos enredosos laberintos del cálculo". Domínguez Ortiz al respecto señaló que la publicación

417 SALAZAR, J,A.: Los estudios eclesiásticos superiores en el Nuevo Reino de Granada,1563-1810. Op. Cit., p. 440. PESSET, N. y PESET, J.L.: La universidad española. Siglos XVIII y XIX. Madrid, Tauros Ediciones, 1974, pp. 222-223.

${ }^{418}$ HIRSCHBERGER, J.: Historia de la filosofía, lomo 2, Op. Cit., 55. Citado por ARBOLEDA, Luis Carlos.: "Mutis entre el rigor wolffiano y la intuición cartesiana", en El perfil de la ciencia en América. Guadalajara, México, XI Congreso Interamericano de Filosofía. 1985, cuaderno Quipu, 1, p. 127.

${ }^{419}$ HIRSCHBERGER, J.: Op. Cit; p. 156. Wolff fue un autor que recomendó desde 1767 Gregorio Mayáns en la reforma de todas las universidades de la metrópoli española. Mayáns prefirió a Wolff frente a Newton, Musschenbroek entre otros. Jovellanos en 1790 lo propone para los colegiales de Calatrava y queda recomendado junto a Van Espen, Grocio, Pufenderf, en el curso teológico del Reglamento literario e institucional del Colegio Imperial de Calatrava. Véase en PESET, N y PESET, J.L.: Op. Cit., pp. 122-219228.

${ }^{420}$ ABBAgnANO, N.: Historia de la filosofía. Buenos Aires, Editorial Suramericana, Tomo III, 1956, p.48. Véase un amplio estudio de comparación entre las teorías de Wolff y las asimiladas y enseñadas por Mutis en el virreinato de la Nueva Granada. ARBOLEDA, Luis Carlos.: "Mutis entre el rigor wolffiano y la intuición cartesiana". Art. Cit., pp. 117 - 129.

Digitalizado por RED ACADEMICA 
Philosophiae Naturalis Principio Mathematica" podrían contarse con los dedos de las manos los que en España estuvieron capacitados para entenderla".

Es importante darse cuenta de que el método científico newtoniano, además de "lento", se oponía al sistema escolástico, y de que Newton era partidario de elaborar paulatinamente una filosofía natural basada en los principios científicos, lo que puede explicar "su lentitud en publicar sus obras, porque aunque el espíritu y talentos de este gran filósofo lo hacía penetrar muy presto en los ocultos misterios de la naturaleza, procuraba repetir sus observaciones, experiencias y meditaciones para dar mayor fuerza a su doctrina" ${ }^{421}$.

La filosofía newtoniana encaja perfectamente en la manera de pensar de los ilustrados criollos. En efecto, cuando trata de conjugar el modernismo más radical, en los aspectos científicos, con la vuelta a las fuentes y a los modos de comportamiento y de vida de los primitivos cristianos. Bien se sabe que "la mecánica de Newton está unida a su teología, su Dios es un geómetra y arquitecto que ha sabido combinar los materiales del sistema de tal manera que resulte un estado de equilibrio estable y un movimiento continuo y periódico" ${ }^{\prime 22}$.

Por lo tanto, algunos autores consideran que la ciencia de Newton deja una gran incertidumbre en lo referente a la filosofía, porque "su mecanismo puede orientarnos lo mismo hacia la teología que hacia el materialismo" ${ }^{423}$. Pero por muy paradójico que parezca lo anterior, es con Newton con quien se marca el avance en la enseñanza de los estudios superiores del siglo XVIII, sin olvidar que "el Renacimiento cultural del siglo está presidido por la influencia del pensamiento de Newton en lo que se refiere a las ciencias, y a lo que entonces se llama filosofía natural".

En esta misma línea de pensamiento de Newton, encontramos el abate Juan Antonio Nollet (1700-1770) quien "atraía a la muchedumbre de París con sus lecciones de física". La obra' más conocida de Nollet, Un Essai sur

I 'électrcité des corps, fue traducida al español por Vásquez Morales un año después de su publicación en francés, en 1747. Otra de las obras de gran difusión de Nollet fue las Lecciones de física experimental, que tradujo al castellano en 1757 el padre Antonio Zecagnini ${ }^{424}$.

\footnotetext{
${ }^{421}$ MUTIS, J.C.: "Elementos de filosofía natural que contienen los principios de la física demostrados por las matemáticas y confirmados con observaciones y experiencias dispuestos para instruir a la juventud en la doctrina de la filosofía newtoniana en el Real Colegio del Rosario de Santa Fe de Bogotá", 1764. en HERNANDEZ DE ALBA., G.: Documentos para la historia de la educación en Colombia. 1710-767, Bogotá, Editorial Kelly, Tomo II, 1976, p. 246. Considera Cassirer que en el método de Newton "la observación es el datum, lo dado, el dato; el principio y la ley es quasitum, lo buscado". Véase en CASSIRER, Ernest.: La filosofía de la llustración. México, Fondo de Cultura Económica, 1943, p. 22. DOMINGUEZ ORTIZ, A.: Sociedad y Estado en el siglo XVIII español, Barcelona, Editorial Ariel.

${ }_{422}^{423}$ ABBAGNANO, N.: Historia de la filosofía. Op. Cit., pp. 11-12.

${ }^{423}$ Ibídem., p. 14.

${ }^{424}$ HERR, R.: España y la revolución del siglo XVIII, Madrid, Editorial Aguilar, 1964, p. 35. ANDERSON, M.S.: Europa en el siglo XVIII. 1713-1783. Valencia. Editorial Aguilar.1964, p1266. SARRAILH, J.: La España llustrada en la segunda mitad del siglo XVII!. Op. Cit., p. 213459. ALVAREZ DE MORALES, A.: La Ilustración y la reforma de la universidad en la España del siglo XVIII. Madrid, Ediciones Pegaso, $3 a$. edición, 1985, p. 27-28. Considera Alvarez de Morales que "la publicación de la Principia de Newton, en 1687, dio un impulso decisivo a la ciencia, iniciando así un proceso cuya característica general será su evolución a espaldas de los establecimientos tradicionales de enseñanza".
} 
En España sus obras tuvieron difusión; se sabe que Peñaflorida lo recomendaba desde 1773 y, en el Colegio de Vergara de la Sociedad de Amigos del País, en 1776, se enseñaron las ciencias naturales siguiendo a Nollet y Buffon ${ }^{425}$.

En general, se considera que con Nollet "la física experimental penetró muy rapidamente en la enseñanza" y "se consagró un experimentalismo cartesiano" ${ }^{426}$.

En el virreinato de la Nueva Granada, Nollet es un autor básico en la cátedra de filosofía de Caballero y Góngora y en la de Eloy Valenzuela.

Los textos del italiano napolitano Antonio Genovesi o Genuense (1712-1769) se encuentran igualmente recomendados en los planes de Antonio Caballero y Góngora, Eloy Valenzuela, Luis Quijano y Pérez Calama, aunque este último lo hace para la cátedra de política personal. Genovesi fue el primero que ejercitó en una universidad europea la nueva ciencia de la economía en la Universidad de Nápoles. Fue también profesor de filosofía y se le reconoce como una "persona profundamente vinculada a la corriente cientifista y experimentalista de la época" ${ }^{27}$. Se le considera de la escuela de Locke y Leibnitz "aparte de estar interesado de siempre por los temas y problemas americanos" ${ }^{28}$.

Pieter Van Musschenbroek, físico alemán profesor de Física experimental, de la Universidad de Leyden, tuvo influencia en los ambientes científicos y universitarios, principalmente centroeuropeos de mediados del Siglo XVIII, con sus obras De Méthodo instituendi experimenta physica y Physicae experimentales. Estas obras se reeditaron varias veces desde 1730. En España, el físico Musschenbroek aparece ligado en la enseñanza con Genovesi. Los textos de este físico se recomiendan entre otras instituciones españolas, en la Universidad de Salamanca y en el instituto de Gijón, además sus obras tuvieron una amplia difusión en América ${ }^{429}$. En el virreinato de la

425 SARRAILH, J.: La España llustrada de la segunda mital del siglo XVIII. Madrid, Fondo de Cultura Económica, 2a, reimpresión, 1979.p. 213.

${ }^{426}$ ARBOLEDA, Luis Carlos.: "Acerca del problema de la difusión científica en la periferia: el caso de la física newtoniana en la Nueva Granada", en Revista Latinoamericana de Historia de las Ciencias y la Tecnología. Vol. 4, No. 1, 1987, pp. 15-16. Las características de este experimentalismo cartesiano, que señala Arboleda, son las siguientes: a) "estaba más en consonancia con el espíritu patriótico de ciencia nacional sancionado por la Academia, b) representaba una salida espitirualista y sensualista más viable a los progresos de la filosofía natural, que el insoportable "materialismo newtoniano", y c) despojaba a los principios de la aridez del método de Newton de geometrización de la naturaleza".

${ }^{427}$ Las lecciones de comercio y economía civil de Genovesi se estudiaron y comentaron hacia 1798 por la Sociedad de Amigos del País en Palma de Mallorca. La audacia de sus teorías le granjeó persecusiones, de las cuales sólo pudo salvarse gracias a la protección del arzobispo de Tarento monseñor Galliano", en SARRATLH.: Op. Cit., pp. 277-278.Genovesi fue profesor en la Universidad de Nápoles de 1741 hasta 1753, en que fue expulsado de ella por los jesuitas por sus ideas avanzadas y volviendo a la universidad una vez fueron expulsados los religiosos" Autor de Elemen.ta Metaphisicae in usum privatorun adolescentium mathematicum in moren adornata ab Antonio Genovesi in Regia napolitana Academia philosophicae professore, 1743. Editó en 1745 los Elementa phisi cae de Musschenbroek. Escribió también un Manual de Teología dogmática que no se publicó hasta después de su muerte en 1771 en Venecia", en ALVAREZ DE MORALES, A.: Op. Cit., p. 104.

${ }^{428}$ MORA MERIDA, J.L.: "Ideario reformador de un cordobés ilustrado: el arzobispo-virrey Don Manuel Caballero y Góngora”, en publicación conmemorativa del V Centenario: Andalucía y América en el Siglo XVIII. Sevilla, Escuela de Estudios Hispanoamericanos, 1985, p. 249.

${ }^{429}$ En la reforma de estudios de la universidad de Salamanca, hacia 1770, se recomienda que se adopten la lógica y la metafísica del Genuense así como la física de Musschenbroek y en el Instituto de Gijón contraponen a Goudin las enseñanzas de Musschenbroek. SARRAILH, J.: La España Ilustrada de la segunda mitad del siglo XVIII, Op. Cit., pp. 101-110, 441. Antonio Álvarez considera que la obra de Musschenbroeck "fue introducida prácticamente en todas las universidades españolas por los planes de estudio de esta época. Su introducción en España se debió a la edición que hizo en Nápoles el profesor Genuense". En ALVAREZ DE MORALES, A.: Op. Cit., p. 143-275-300. A Musschenbroek se le considera Digitalizado por RED ACADEMICA 
Nueva Granada los encontramos señalados como textos básicos en los planes de estudio de Eloy Valenzuela, Caballero y Góngora y Luis Quijano.

El libro del matemático francés Francois Jaquíer, franciscano, (1711-1783), Institute Philosophica ad estudia theologica potissiunn accommodatae (1757), es uno de los más utilizados para estudiar la Lógica, la Metafísica y la Filosofía Moral. Su obra se recomienda para el plan de filosofía en la asignatura de ética en el plan de Alcalá, en el de Eloy Valenzuela, en el Colegio Pinillos, en el de Pérez Calama y en el de Luis Quijano en Quito. En este último plan, Jaquier se convierte en un autor básico para los tres años de estudio en la cátedra de filosofía ${ }^{430}$.

Gregorio Mayáns, español, es recomendado en el plan de Moreno y Escandón para la enseñanza de la filosofía Moral. Mayáns es reconocido por su espíritu moderno, regalista y por abogar por enseñar en la lengua nacional. No veía con simpatía la escolástica tomista, ni gustaba del dominio de los religiosos y colegiales sobre la universidad" ${ }^{431}$. En 1767 Mayáns presentó a Roda su proyecto de reforma para todas las universidades.

Juan Lorenzo Berti (1.696 - 1.788) teólogo, agustino calzado italiano, recibió la orden de escribir el libro que debería seguir la orden en la enseñanza de la filosofía y teología. Sus obras, Disciplinas Teológicas, en 8 tomos, (Roma, 1.739-45) e Historia eclesiástica sive dissertationes historicae (Florencia, 1.753), tuvieron gran acogida en su época pero a su vez fueron atacadas por jansenistas. Sin embargo, este agustiniano rigorista, profesor de historia eclesiástica en Pisa logró, bajo el auspicio de Benedicto XIV, que sus obras no se catalogaran como prohibidas y, por el contrario, fueron recomendadas por su "doctrina sana" ${ }^{332}$.

En el virreinato de la Nueva Granada los textos de Berti fueron impuestos por el padre General Javier Vásquez. En la ciudad de Santa Fe, en la Universidad de San Nicolás de Bari, el padre Juan Bautista González cumple la orden de su superior general de utilizar los textos de Berti en la enseñanza de la filosofía, hecho que es comunicado mediante circular del 8 de octubre de 1773.

No sabemos si el padre Felipe Mendoza, encargado de la cátedra de filosofía en esta universidad durante los años 1773-1776, llevaría a la práctica las nuevas orientaciones filosóficas. Sin embargo, podemos afirmar que cuando el padre Diego Francisco Padilla

discípulo y sucesor del físico holandés S'Gravesande. Véase en CASSIRER, E.: La Filosofía de la Ilustración. Op. Cit., p. 82. Señala Arboleda que" los Elementa physicae (1734) y' particularmente, la Introduction ad philosophiam naturalem (1762), tuvieron amplia difusión en Europa y América en sus ediciones originales o en sus traducciones". Sustenta esta aceptación y mayor difusión, porque a) no toma partido contra Descartes, b) es un mediador entre S'Gravesande y la tradición, c) los libros están apoyados en experimentos originales. ARBOLEDA, Luis Carlos.: "Acerca del problema de la difusión científica en la periferia: el caso de la física newtoniana en la Nueva Granada”, en Art. Cit., p. 14.

${ }^{430}$ lbídem., p. 163. Jacquier fue uno de los fundadores del centro científico de Trinitá dei Monti en Roma y cuidador de la edición ginebrina de los Principia Matehematica de Newton, también fue profesor de química y física experimental", en ALVAREZ DE MORALES,A.: Op. Cit., p. 104-261.

${ }^{431}$ SARRAILH.: Op. Cit., P. 405. Mayáns señalaba que el Monarca debía reformar los estudios porque "en lo que toca a la enseñanza pública el príncipe debe procurar que en las Universidades se enseñen aquellas ciencias que sean convenientes para conseguir la felicidad de la república cristiana y civil", citado por ALVAREZ DE MORALES, A.: Op. Cit., p. 30, PESET, M, y PESET, L.: La universidad española siglos XVIII XIX. Madrid. Taurus Ediciones, 1974, p. 314.

432 LANTERI. "Los últimos siglos. Escritores agustinos". Parte 3a. pp.360-362. GUTIERREZ, D. : “los estudios en la orden agustiniana"en ANALETA AGUSTINIANA, Vol. XXXIII, 1970. pp. 11-119. MORA MERIDA., J.L.: "Ideario

reformador de un cordobés ilustrado: el arzobispo y virrey don Antonio Caballero y Góngora". Art. Cit., pp.246-247. 
regentó la cátedra de filosofía de 1776 a 1778, no sólo enseñó a Berti sino también a Descartes, Bacon, Newton, Montesquieu y Pascal, autores que oficializó siendo regente de la universidad en 1788, cuando reorganizó este centro educativo. En las universidades de la metrópoli española, señalan los hermanos Peset, que "Hacia 1771 las reformas del Consejo de Castilla deciden que la Summa de Santo Tomás será el libro de texto obligado en las universidades españolas, en contra de obras de Juan Lorenzo Berti recomendadas por los agustinos", pero en el período de 1789 a 1800 las ideas agustinas volvieron a ganar partidarios".

Debemos señalar que en estos planes ilustrados la consigna de leer el texto, como opuesta a la metodología del dictado que fue duramente criticada por Feijoo y Mayáns, se enfrentaba a la cruda realidad de la falta de libros. No obstante, si bien es cierto lo anterior, y ante la necesidad de una adecuada instrucción, Moreno recomienda a los rectores que destinen partidas de dinero para comprar "los libros más necesarios, que repartían entre los estudiantes"; también el fiscal se propone, la fundación de una biblioteca pública, que se logra inaugurar y abrir al público el 9 de enero de 1777. La Real Cédula de su fundación es obtenida en 1788 con el apoyo del virrey Caballero y Góngora.

\section{Conclusión}

En general puede decirse que la corriente ilustrada que penetraba en el virreinato de la Nueva Granada, en la segunda mitad del siglo XVIII, coincidiendo con el reinado de Carlos III, impulsaba una nueva filosofía: "la útil", que llevaba implícita la enseñanza de la filosofía natural newtoniana.

La cátedra de filosofía planteada en los planes ilustrados como los de Moreno, Caballero y Góngora, Valenzuela, Vásquez, Luis Quijano, señalaron teorías y concepciones que se contraponían a la escolástica. El nuevo método se hacía incompatible con el dictado, forma de enseñanza escolástica, por lo que se propuso la lectura directa del texto, con autores de reconocida tendencia anti-escolástica.

Quizá de los planes ilustrados analizados, los más "atrevidos" en señalar textos guías para la enseñanza de la filosofía de marcada línea ilustrada de diferentes países (Italia, Francia, Alemania, Inglaterra), fueron los de Caballero y Góngora y Eloy Valenzuela. Sin embargo, el único plan que se aplicó en la ciudad de Santa Fe dentro del sector civil, fue el de Moreno. Esta reforma, a pesar de su efecto restringido por el poco tiempo de aplicación, combatió "la monotonía y el atraso espiritual escolástico".

Las nuevas tesis filosóficas fueron apoyadas por Mutis, Valenzuela, Vallecilla, Vásquez, Padilla, entre otros, que propiciaron cambios significativos en el pensamiento de la élite criolla. La reforma del padre Vásquez también se aplicó en Santa Fe y Quito, pero debe tenerse en cuenta que en esta institución sólo se formaba al clero de su orden, aunque también fue frecuentada "por extraños laicos" 433 y promovió conclusiones públicas sobre Copérnico, hecho que en su época fue motivo de gran polémica ${ }^{434}$. El plan de filosofía de Luis Quijano para el colegio San Fernando de Quito, presenta un marcado carácter ilustrado. Sin embargo, se desconoce si en la aplicación, que se realizó del citado plan, se

\footnotetext{
${ }^{433}$ MORA MERIDA, J.L.: "Ideario reformador, p. 71.

${ }^{434}$ NEGRIN, O. y SOTO, D.: "Mutis y los agustinos en la defensa de las teorías de Copérnico en la ciudad de Santa Fe. Siglo XVIII", en VI Congreso de Historia en Colombia , Ibagué, Universidad del Tolima, noviembre de 1987.
} 
enseñó los nuevos contenidos de la filosofía moderna con los respectivos textos y autores ilustrados que se señalaban.

Queremos insistir, porque quizá sea significativo, que los ilustrados que plantearon reformas en el virreinato se caracterizaron por una mentalidad religiosa que conciliaban con una filosofía ecléctica, para poder defender e introducir los avances científicos en las aulas universitarias. De la misma manera, se encuentra que los nuevos planteamientos educativos tienen una influencia marcada de los ya expuestos en la península por Feijoo, Mayáns, Olavide, entre otros. Sin embargo, la asimilación y aplicación de estas ideas ilustradas se dan de una manera particular teniendo en cuenta la naturaleza de la población, criollos, y las circunstancias sociales, económicas y culturales diferentes a la metrópoli.

En sentido general, es claro que detrás de los planteamientos expuestos en estos planes de filosofía ilustrados, se encontraba un trasfondo ideológico mucho más amplio. Los planes de estudio solo fueron una faceta más de la producción científica-cultural de los ilustrados criollos y metropolitanos. Es posible que los planteamientos de la nueva generación de criollos ilustrados, sobre las ciencias útiles y el cultivo de la responsabilidad y en patriotismo, tuviesen una mayor repercusión y se cristalizarán fuera de los claustros universitarios, en actividades tales como escritos en los periódicos y la participación en sociedades científicas y literarias. 